\title{
BUILDING MARKETING UNTUK KOMUNITAS SENDIRI BERBASIS ONLINE
}

\author{
Padeli $^{1}$ \\ Sudaryono ${ }^{2}$ \\ Indri Handayani ${ }^{3}$ \\ e-mail: padeli@raharja.info; sudaryono@raharja.info; indri@raharja.info
}

Diterima : 25 Maret 2014 / Disetujui : 16 April 2014

\begin{abstract}
World wide web or web is often called one of the internet facilities are becoming increasingly well known that many people often view it as the only way to surf the internet. By having a website or a homepage means a community has its own place on the web, in which all people worldwide the opportunity to redirect the browser and find out more about what is published. In order to attract and keep visiting the website design and loading required and information is good news. This is an opportunity that should be best utilized to inform or whatever is the superior product and service profile for a company or agency that wants more widely known. Internet is the best solution to find information quickly and efficiently, and therefore the sale is a web-based online media that are considered practical because people do not need to come directly to find the desired item. The conclusion of this study are as follows: 1. This program can provide convenience to consumers in finding and buying products sold by Bizarre Sounds Production, sales order, booking and information service for the better stuff. 2. The information displayed is not just news-news about the world of metal music but also the latest promotions Bizarre Sounds Production of products in order to increase sales and profits of the company.
\end{abstract}

Keywords: World wide web, Information Systems, website, online media.

1. Dosen Jurusan Sistem Informasi, STMIK Raharja

Jl. Jend Sudirman No. 40 Modern Cikokol-Tangerang Telp. 5529692

2. Dosen Jurusan Sistem Informasi, STMIK Raharja

Jl. Jend Sudirman No. 40 Modern Cikokol-Tangerang Telp. 5529692

3. Mahasiswa Jurusan Sistem Informasi, STMIK Raharja

Jl. Jend Sudirman No. 40 Modern Cikokol-Tangerang Telp. 5529692 


\begin{abstract}
ABSTRAKSI
World wide web atau yang sering disebut web adalah satu dari sekian fasilitas internet yang semakin lama semakin terkenal sehingga banyak orang sering memandangnya sebagai satu-satunya cara untuk menjelajah internet. Dengan memiliki Website atau Homepage berarti suatu komunitas memiliki tempat sendiri di web, dimana semua orang di seluruh dunia berkesempatan untuk mengarahkan browsernya dan mengetahui lebih banyak tentang apa yang dipublikasikan. Agar website menarik dan senantiasa dikunjungi diperlukan desain dan pemuatan berita serta informasi yang baik. Ini adalah kesempatan yang mesti dimanfaatkan sebaik-baiknya untuk menginformasikan apapun yang menjadi layanan atau produk unggulan serta profil bagi sebuah perusahaan atau instansi yang ingin semakin dikenal lebih luas. Internet menjadi solusi terbaik untuk mencari informasi yang cepat dan efisien, oleh karena itu penjualan berbasis website merupakan media online yang dianggap praktis karena orang tidak perlu datang langsung untuk mencari barang yang diinginkan. Kesimpulan dari penelitian ini adalah sebagai berikut: 1. Program ini dapat memberikan kemudahan kepada konsumen dalam mencari dan membeli produkproduk yang dijual oleh Bizarre Sounds Production, agar penjualan, pemesanan dan informasi servis barang menjadi lebih baik. 2. Informasi yang ditampilkan tidak hanya berita - berita seputar dunia musik metal tetapi juga promosi-promosi terbaru dari produk Bizarre Sounds Production agar dapat meningkatkan penjualan dan keuntungan dari perusahaan.
\end{abstract}

Kata Kunci : World wide web, Sistem Informasi, website, media online

\title{
PENDAHULUAN
}

Dewasa ini perkembangan ilmu pengetahuan dan teknologi komunikasi semakin maju terutama dibidang komputerisasi. Hal ini merupakan suatu keuntungan bagi semua usaha dan segala aspek bidang yang lain, karena teknologi komputer ini sudah menjadi kebutuhan yang sangat mendasar bagi manusia, dan dapat memberikan informasi secara mudah dan cepat. Beberapa alasan kenapa komputer saat ini sangat dibutuhkan dalam pemenuhan kebutuhan informasi yaitu, adanya keinginan user untuk mendapatkan informasi secara mudah, cepat dan akurat, mampu menangani sistem informasi yang memiliki database yang sangat besar dan alasan-alasan lainnya. Banyak sekali perangkat lunak yang tersedia untuk membuat sistem informasi, salah satunya yaitu dengan menggunakan perangkat lunak berbasis web. Kini proses tersebut sangat terbantu dengan adanya internet (Davis, 2005: 54).

Saat ini website menjadi solusi terbaik untuk melakukan bisnis khususnya dibidang penjualan dengan publikasi melalui internet segala sesuatunya semakin mudah 
dan ribuan orang dapat menyaksikan serta melihat langsung tentang apa yang akan kita informasikan sehingga secara tidak langsung dapat meningkatkan keuntungan dari perusahaan tersebut (Ludwing, 2007: 4). Dengan memiliki Website atau Homepage berarti kita memiliki tempat sendiri di web, dimana semua orang diseluruh dunia berkesempatan untuk mengarahkan browsernya dan mengetahui lebih banyak tentang apa yang kita informasikan. Ini adalah kesempatan yang harus dimanfaatkan sebaik-baiknya untuk menginformasikan apapun yang menjadi layanan atau produk unggulan serta profil bagi sebuah perusahaan atau instansi yang ingin semakin dikenal lebihluas.

Seiring dengan kemajuan zaman maka orang lebih memilih hal-hal yang praktis dan tidak membuang banyak waktu, sehingga internet menjadi solusi terbaik untuk mencari informasi yang cepat dan efisien, oleh karena itu penjualan berbasis website dianggap praktis karena orang tidak perlu datang langsung untuk mencari barang yang di inginkan, tetapi hanya dengan duduk didepan komputer kita bisa membeli barang yang dijual diseluruh dunia (Edhy, 2003: 123).

Salah satunya penjualan pada produk Bizzare Sounds Production(BSP) akan sangat bermanfaat untuk masyarakat khususnya pecinta musik karena selain bisa bertukar informasi dikalangan komunitas musik bawah tanah atau bisa disebut metal head BSP juga menjual berbagai barang-barang atau produk-produk seperti kaset atau cd yang tidak akan ditemukan di toko-toko musik lainnya, tidak hanya itu BSP juga merupakan salah satu label musik independent yang cukup dikenal dikalangan pecinta musik metal tanah air. Selama ini kegiatan promosi yang dilakukan oleh Bizarre Sounds Production belum terlalu meluas karena hanya terbatas pada brosur yang diberikan kepada customer. Dengan tugasnya tersebut Bizzare Sounds Production dirasa perlu untuk mempublikasikan produk serta berbagai informasi lainnya yang bermanfaat bagi masyarakat luas dalam bentuk berupa website dengan desain yang baik agar pengunjung merasa tertarik dan berita yang informatif yang terus update.

\section{PERMASALAHAN}

Berdasarkan uraian di atas maka yang menjadi rumusan masalah dalam penelitian ini adalah:

1) Bagaimana menciptakan suatu sistem penjualan dan pemesanan yang dapat memudahkan konsumen dalam mencari produk-produk yang dijual oleh 
komunitas atau kalangan tertentu, agar penjualan, pemesanan dan informasi servis barang menjadi lebih baik?

2) Strategi apa yang harus dilakukan agar informasi barang, pejualan dan pemasarannya dapat lebih dikenal oleh masyarakat luas sehingga secara otomatis dapat meningkatkan keuntungan dari perusahaan?

\section{CRITICAL REVIEW}

E-commerce merupakan perkembangan dan bagian dari era teknologi informasi yang mampu menciptakan ekonomi baru. Internet saat ini sudah umum digunakan oleh dunia usaha dalam rangka mencari informasi dagang, promosi dagang, hubungan/ kontrak dagang secara internasional ke seluruh Negara/dunia. Sarana ini walaupun tahap awal investasinya cukup mahal, namun proses bisnis selanjutnya akan lebih cepat dan sekaligus dapat mengakses data maupun informasi bisnis dalam tempo yang cepat. Hampir seluruh instansi pemerintah termasuk perwakilan Pemerintah Republik Indonesia di luar negeri (kedutaan besar, konsultan jenderal, maupun atase perdagangan), salah satu upaya komunikasi dan promosi sudah menggunakan ecommerce. Ilustrasi mengenai hal dapat dilihat pada gambar 1 berikut (Buchori, 2005: 24).

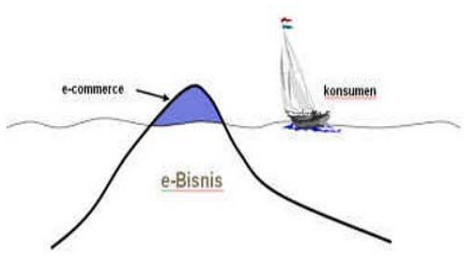

Gambar 1 E-commerce adalah Sisi-muka (Customer Interface) dari e-Bisnis

Usaha yang menggunakan e-commerce yang dapat diakses menggunakan internet merupakan suatu usaha yang sangat unik, karena hanya dengan menggunakan satu media, peruahaan dapat melakukan usaha/bisnis, baik dengan sesama perusahaan (Business to Business - B2B) atau dapat proses bisnis langsung antara pebisnis dengan konsumen atau penjual dengan pembeli (Business to Consumer B2B). Mereka dapat melakukan proses bisnis, mulai dari promosi produk, penawaran, dan permintaan produk, tanya jawab antara konsumen dan produsen atau antara pembeli dengan penjual dapat dilakukan secara efektif dengan ecommerce. 
Model e-commerce seperti: Customer to Business (C2B atau self service), Business to Business (B2B, contohnya pengadaan barang), e-auction dan emarketplace (C2C, lelang on line) secara visual dapat dilihat pada gambar 2 berikut (Kao, 1998: 213).

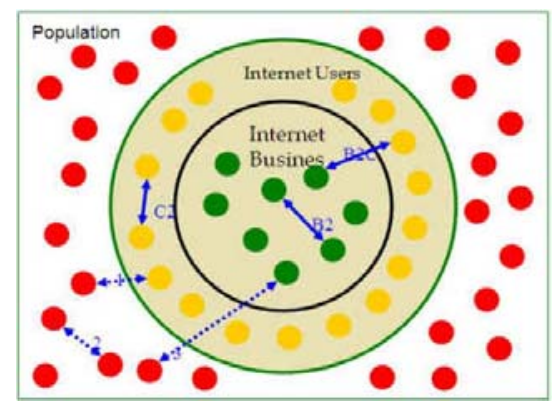

Gambar 2 Model e-commerce

B2B artinya proses bisnis antara penjual dengan penjual atau produsen dengan produsen atau produsen dengan grosir, pedagang, agen, dan sejenisnya dilakukan secara online. Mereka dapat melakukan proses bisnis, mulai dari promosi, penawaran dan permintaan produk, tanya jawab antara mereka dapat dilakukan dengan cara online melalui internet atau mobile phone yang memiliki fitur untuk itu.

Tidak dapat dipungkiri bahwa kekuatan teknologi internet dan mobile memang semakin hebat. Teknologi pencarian informasi bisnis maupun informasi lainnya misal melalui situs Google.com, diibaratkan oleh Hermawan Kertajaya sebagai malaikat pencatat amal baik dan buruk. Ketik nama mereka Anda di sana, dan akan terlihat betul perbuatan apa yang telah Anda lakukan selama ini. Kalau banyak positif, tentunya baik karena dapat mempengaruhi otak, hati, dan jiwa konsumen. Kita semua tahu bahwa Google, yang notabenenya perusahaan pemasang iklan merupakan fenomena internet yang telah menjadi bagian dari wawasan kita dalam mencari informasi mulai dari produk atau jasa yang terbesar sampai yang terkecil, melihat dunia luar (contohnya Google Earth), mendengar (Google Alert), dan berkolaborasi dengan rekan sekantor (Google Docs, Gmail, Google Talk).

Tidak hanya merevolusi industri teknologi informasi, Google juga mengubah banyak tatanan industri mulai dari media (Google news, YouTube atau Google Video) sampai perpustakaan (Google Books, Google Schoolar). Google adalah internet, dan internet adalah Google. Dengan misinya yang sangat horizontal, yaitu "Mengelola Informasi Dunia dan Membuatnya Mudah diakses dan Berguna” Google telah menjadi 
bagian dari kehidupan masyarakat tulen dunia, New Wave yang ingin mencari, melacak, dan menggunakan sebuah informasi. Teknologi Web 1.0 adalah era kita hanya dapat mencari, browsing, dan read-only. Kini dunia internet telah berubah. Teknologi internet masuk pada Web 2.0 telah membuat internet bersifat lebih interaktif dan dinamis. Interaksi dengan komunitas menjadi lebih memungkinkan karena pada dasarnya kekuatan sesungguhnya dari aplikasi internet yang bersifat Web. 2.0 adalah read and write. Intrernet dengan Web 2.0 membuat proses horizontal semakin cepat (Hisrich, Michael P. Peter, 1998: 154).

Industri teknologi informasi melihat kegiatan e-commerce ini sebagai aplikasi dan penerapan dari e-business yang berkaitan dengan transaksi komersial, seperti: transfer dana secara elektronik, SCM (Supply Chain Management), e-marketing, atau online marketing, online transaction processing, Electronic Data Interchange / EDI, dan lain-lain. E-commerce pertama kali diperkenalkan pada tahun 1994 pada saat pertama kali banner-elektronik dipakai untuk tujuan promosi dan periklanan di suatu halaman-web (website). Menurut Riset Forrester, perdagangan elektronik menghasilkan penjualan seharga AS\$12,2 milyar pada 2003. Menurut laporan yang lain pada bulan oktober 2006 yang lalu, pendapatan ritel online yang bersifat nontravel di Amerika Serikat diramalkan akan mencapai seperempat trilyun dolar US pada tahun 2011.

Dalam banyak kasus, sebuah perusahaan e-commerce bisa bertahan tidak hanya mengandalkan kekuatan produk saja, tapi dengan adanya tim manajemen yang handal, pengiriman yang tepat waktu, pelayanan yang bagus, struktur organisasi bisnis yang baik, jaringan infrastruktur dan keamanan, desain situs web yang bagus, beberapa faktor yang mendukung hal tersebut adalah (Ladjamuddin B, 2004: 176):

1) menyediakan harga kompetitif;

2) menyediakan jasa pembelian yang tanggap, cepat, dan ramah;

3) menyediakan informasi barang dan jasa yang lengkap dan jelas;

4) menyediakan banyak bonus seperti penawaran istimewa, dan diskon:

5) memberikan perhatian khusus seperti usulan pembelian;

6) menyediakan layanan untuk berdiskusi, masukan dari pelanggan; dan

7) mempermudah kegiatan perdagangan. 


\section{PEMECAHAN MASALAH}

Dalam penelitian ini digunakan beberapa metode penyelesaian masalah dengan rancangan sistem yang dianalisis melalui empat tahapan sebagai berikut:

\section{a. Metode Pengumpulan Data:}

1. Angket (Questionnare). Merupakan suatu teknik pengumpulan data secara tidak langsung yang berisi sejumlah pertanyaan yang harus dijawab oleh responden yang dalam penelitian ini disebut requirement elicitation tahap 1.

2. Wawancara (Interview). Suatu cara pengumpulan data yang digunakan untuk memperoleh informasi langsung dari sumbernya yang dalam penelitian ini disebut requirement elicitation tahap 2.

3. Pengamatan (Observation). Melakukan pengamatan secara langsung ke objek penelitian untuk melihat dari dekat kegiatan yang dilakukan dan diperoleh elisitasi final untuk menentukan program yang diperlukan dalam menyelesaikan masalah yang dihadapi stakeholder.

\section{b. Perancangan dan Implementasi:}

1. Perancangan database digunakan sebagai media penyimpanan data yang dipergunakan dalam aplikasi ini dan database membantu pemrograman dalam menampilkan data, sehingga terhindar dari kesalahan dan tepat guna pada implementasinya nanti.

2. Berdasarkan hasil analisa pada sistem penjualan online yang berjalan pada salah satu komunitas produk Bizarre Sounds Production, maka sistem yang diusulkan adalah dengan penambahan beberapa database baru untuk menunjang transaksi pembelian yang dilakukan, sehingga diharapkan system usulan ini dapat meningkatkan ketelitian proses transaksi penjualan, pencarian data dengan cepat dan pembuatan laporan menjadi mudah.

3. Setelah sistem desain telah dilakukan percobaan maka diteruskan pada tahapan implementasi pada produk Bizarre Sounds Production.

\section{IMPLEMENTASI DAN PEMBAHASAN}

Berdasarkan hasil analisa yang sudah dilakukan pada sistem penjualan online yang berjalan pada salah satu komunitas produk Bizarre Sounds Production, maka 
sistem yang diusulkan adalah dengan penambahan beberapa database baru untuk menunjang transaksi pembelian yang dilakukan, sehingga diharapkan system usulan ini dapat meningkatkan ketelitian proses transaksi penjualan, pencarian data dengan cepat dan pembuatan laporan menjadi mudah.

\section{Rancangan Database}

Rancangan database digunakan sebagai media penyimpanan data yang dipergunakan dalam aplikasi ini dan database membantu pemrograman dalam menampilkan data. Pada tabel ini akan dijelaskan nama field, lebar, dan keterangan mengenai database tersebut. Hasil analisa pada sistem yang dihasilkan terdapat beberapa rancangan yang diusulkan (Jogiyanto, 2005: 98). Dari rancangan tersebut selanjutnya akan dibentuk rancangan basis data untuk mempermudah melihat bentuk file dan isinya. Berikut ini adalah penjelasan tentang proses perancangan basis data dari Entity Relationship Diagram (ERD), tampilan Logical Record Structure ( LRS ) dan tabel rancangan basis data.

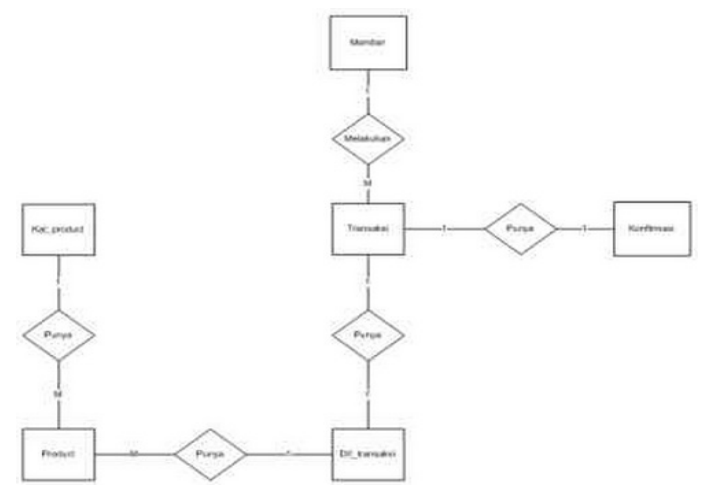

Gambar 1. Rancangan E-R Diagram

Berdasarkan gambar 1 di atas pada rancangan E-R diagram dapat dideskripsikan sebagai berikut: member melakukan pengecekan barang dan mengkonfirmasi apakah barang dipesan tersedia, bila ada maka dilakukan transaksi pembelian sesuai dengan kesepakatan (Kristianto, 2005: 56). Produk-produk yang dimiliki dapat dilihat di katalog produk sebelum dilakukan transaksi. Adapaun rancangan tampilan Logial Record Structure (LRS) yang dibentuk dengan nomor dari tiap record ilustrasinya dapat dilihat pada gambar 2 berikut. 
Berdasarkan gambar 1 di atas pada rancangan E-R diagram dapat dideskripsikan sebagai berikut: member melakukan pengecekan barang dan mengkonfirmasi apakah barang dipesan tersedia, bila ada maka dilakukan transaksi pembelian sesuai dengan kesepakatan (Kristianto, 2005: 56). Produk-produk yang dimiliki dapat dilihat di katalog produk sebelum dilakukan transaksi. Adapaun rancangan tampilan Logial Record Structure (LRS) yang dibentuk dengan nomor dari tiap record ilustrasinya dapat dilihat pada gambar 2 berikut.

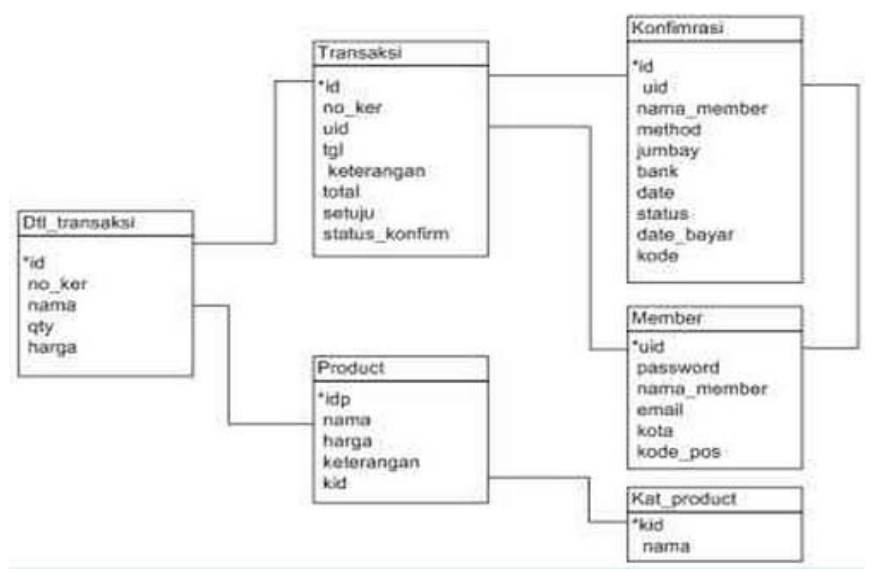

Gambar 2. Rancangan Tampilan LRS

Berdasarkan gambar 2 di atas ditampilkan rancangan Logial Record Structure yang merupakan diagram alur dalam bahasa pemrograman. Sebagai kesimpulan, perhatikan kerja (work flow) saat permintaan (request) memasuki sistem seperti yang digambarkan di atas. Perhatikan bagaimana detil transaksi mengendalikan aliran kerja, mengambil objek yang dikembalikan oleh member dan kemudian mendelegasikannya ke dalam *idp untuk melokalisasi dan sekaligus mengkoordinasikan siklus hidup lengkap dengan permintaan, proses ini disebut processing pipeline.

Pada gambar 3 berikut dijelaskan diagram alur saat mulai sampai berakhir pada layar tampilan menu utama. Tahapannya adalah tampilan menu utama masuk ke home atau web, kemudian melakukan pemesanan. Apabila pemesanan sudah fix maka dapat dicek pada status pesan, maka akan tampil login member. Setelah diisi maka konsumen akan melihat serial number pada tampilan tentang kami. Demikian 
seterusnya sampai gallery produk ditampilkan dan pelanggan siap membeli secara online.

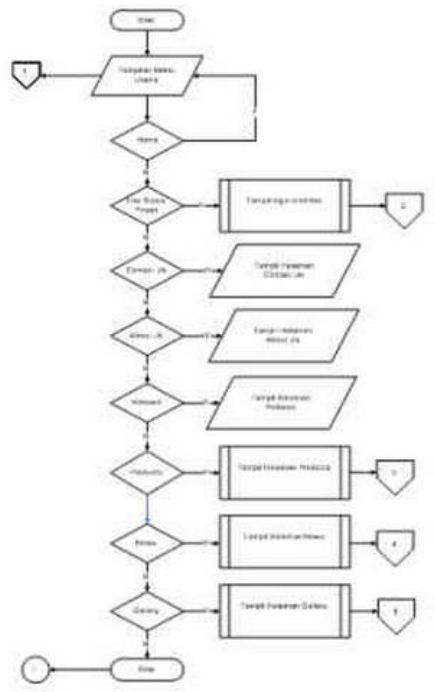

Gambar 3. Flowchart Tampilan Menu Utama

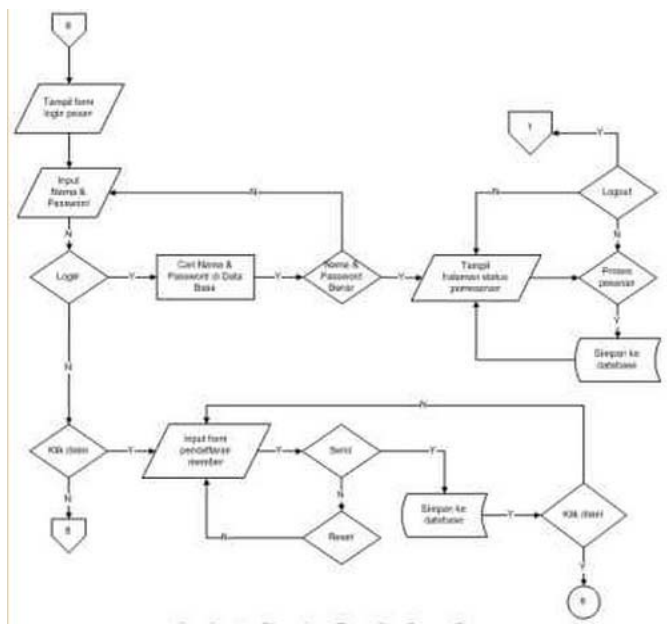

Gambar 4. Flowchart Tampilan Proses Pesanan 


\section{Tampilan Layar Home}

\section{Tampilan Meu utama web site pemasaran}

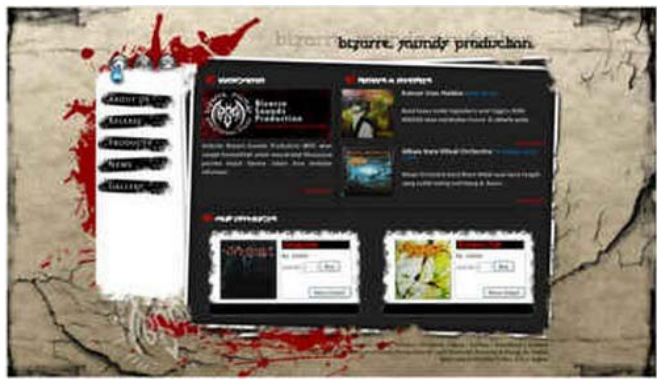

Gambar 4. Tampilan Halaman Home

Pada gambar 4 di atas merupakan tampilan halaman home. Pada tampilan menu utama/home ini terdapat beberapa link diantaranya HOME, LOGIN MEMBER, CONTACT US, ABOUT US, RELEASE, PRODUCTS, NEWS dan juga GALLERY yang akan menuju ke masing-masing halaman dari link tersebut.

\section{Tampilan Layar About Us}

Pada menu About Us menampilkan profile, sejarah singkat serta visi dan misi dari Bizarre Sounds Production. seperti terlihat pada gambar 5 di bawah ini.

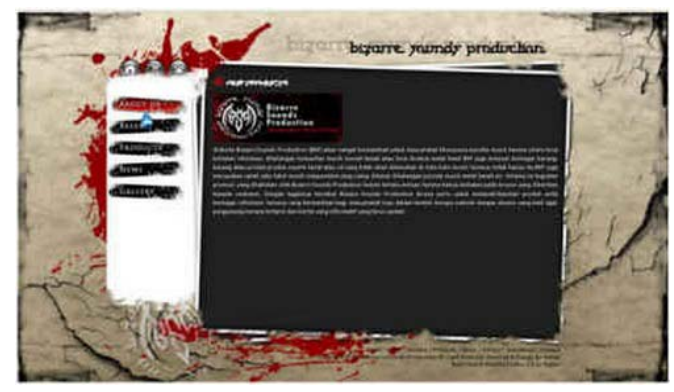

Gambar 5. Tampilan Halaman About Us

\section{Tampilan Layar Release}

Pada halaman release akan ditampilkan album dari band - band yang telah di release oleh Bizarre Sounds Production. 


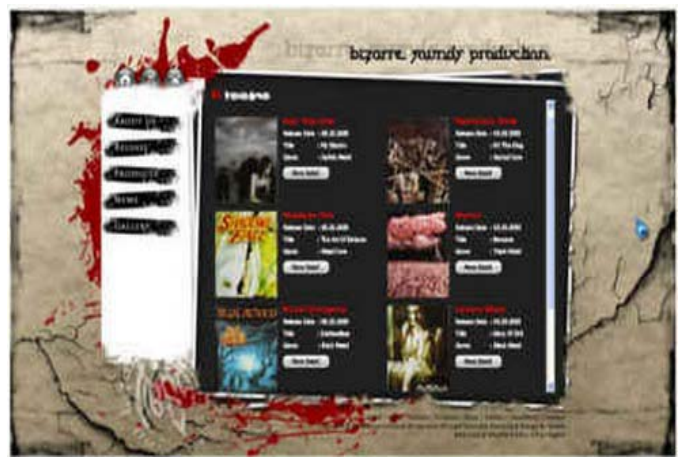

Gambar 6. Tampilan Halaman Release

\section{Tampilan Layar Detail Product}

Pada tampilan layar Detail product ini akan ditampilkan detail dari produk produk yang di jual oleh Bizarre Sounds Production, di dalam halaman ini juga terdapat tombol buy dan jumlah pemesanan.

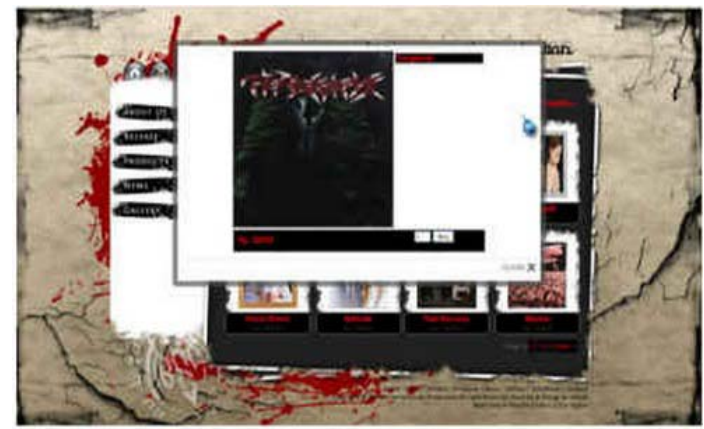

Gambar 7. Tampilan Halaman Detail Product

\section{Tampilan Layar Shopping Cart}

Pada halaman shopping cart anda bisa melihat daftar barang yang sedang anda pesan, pada halaman ini juga terdapat beberapa link yaitu How To Buy, Back To Product, Proses Your Order dan Delete Cart yang akan menuju ke masingmasing halaman dari link tersebut. 


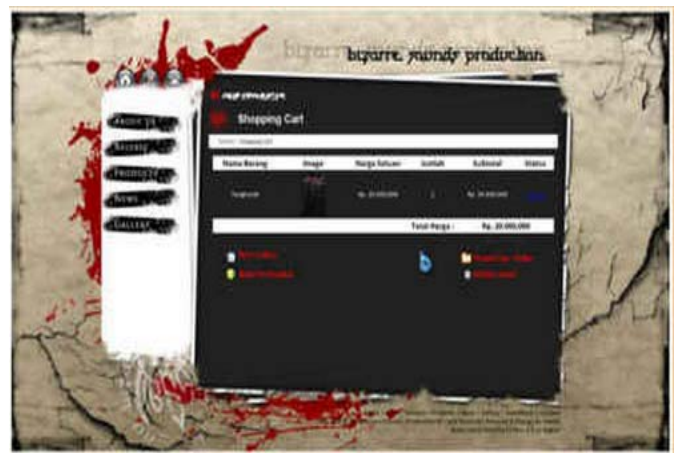

Gambar 8. Tampilan Halaman Shopping Cart

\section{Tampilan Layar Gallery}

Pada halaman Gallery pengunjung website bisa mendownload lagu dari band - band yang telah di release oleh Bizarre Sounds Production.

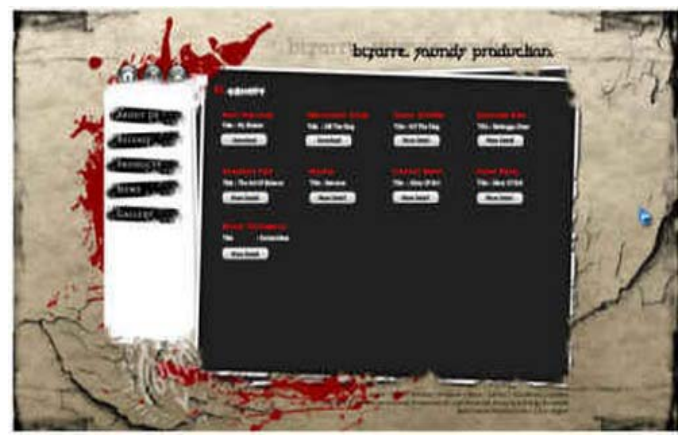

Gambar 9. Tampilan Halaman Gallery

\section{Tampilan Layar Login Admin}

Pada halaman Login Admin terdapat form yang berisi Username \& Password yang akan terhubung ke halaman status pesanan Admin. 


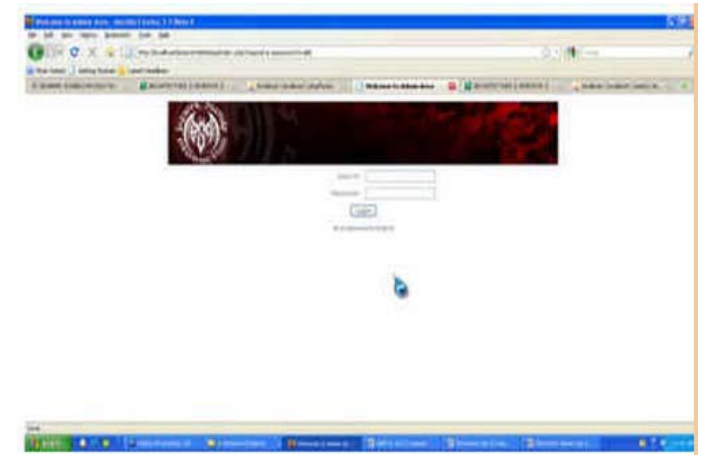

Gambar 10. Tampilan Halaman Login Admin

\section{Tampilan Layar Admin}

Pada halaman Member terdapat beberapa menu yang berfungsi untuk mengupdate data dan isi website, menu - menu tersebut akan menuju ke masingmasing halaman dari link tersebut.

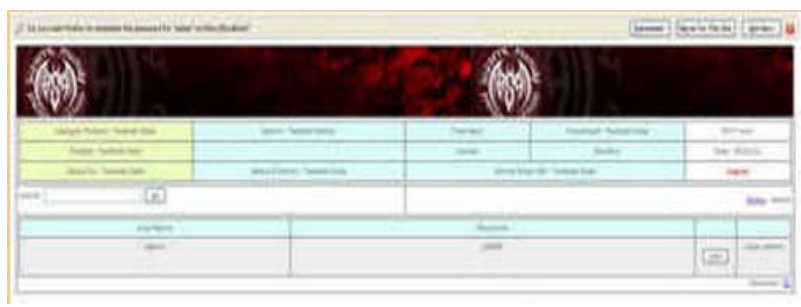

Gambar 11. Tampilan Halaman Admin

\section{Tampilan Layar Update Transaksi}

Pada halaman Transaksi, admin dapat memeriksa status dari member, jika member sudah melakukan pembayaran maka admin akan mengubah status member tersebut sehingga member bisa memeriksanya di halaman status pesanan member dan barang yang sudah dipesan oleh member akan dikirim ke alamat. 


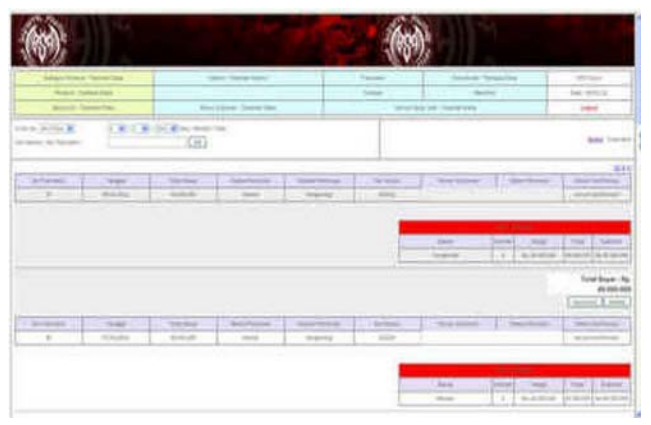

Gambar 12. Tampilan Halaman Update Transaksi

\section{KESIMPULAN}

Berdasarkan pada program aplikasi Website pada Bizarre Sounds Production ini, maka peneliti dapat menarik beberapa kesimpulan, diantaranya adalah sebagai berikut:

1. Program ini dapat memberikan kemudahan kepada konsumen dalam mencari dan membeli produk - produk yang dijual oleh Bizarre Sounds Production, agar penjualan, pemesanan dan informasi servis barang menjadi lebih baik.

2. Informasi yang ditampilkan tidak hanya berita - berita seputar dunia musik metal tetapi juga promosi-promosi terbaru dari produk Bizarre Sounds Production agar dapat meningkatkan penjualan dan keuntungan dari perusahaan.

\section{DAFTAR PUSTAKA}

1. Alma, Buchori. (2005). Kewirausahaan: untuk Mahasiswa dan Umum, Alfabeta: Bandung.

2. Davis, B. Gordon. (2005). Sistem Informasi Manajemen II. Jakarta: PPM.

3. Edhy Sutanta. (2003). Sistem Informasi Manajemen. Yogyakarta: Graha Ilmu.

4. Hisrich, Robert D dan Michael P. Peter. (1998). Entrepreneurship, Boston, MA : Irwin International, Inc.

5. Imansyah, Muhammad. (2003). PHP dan MySql untuk Orang Awam. Palembang: Maxikom. 
6. Kristianto, Budhi. (2005). Referensi Coding Pemrograman Web HTML, ASP, PHP Tingkat Dasar. Yogyakarta: Anindya.

7. Kao, J.J. (1998). The Entrepreneurial Organization, New Jersey: Prentice Hall International Inc.

8. Ladjamuddin B, Al-Bahra. (2004). Konsep Sistem Basis Data dan Implementasinya. Edisi Pertama, Yogyakarta: Graha Ilmu.

9. Ludwing. (2007). Konsep Sistem Informasi. Diakses pada tanggal 18 Desember 2010 dari: http://simkesugm07.files.wordpress.com.

10. Jogiyanto. (2005). Analisis \& Design Sistem Informasi: Pendekatan Terstruktur Teori dan Praktek Aplikasi Bisnis. Edisi Ke-3. Yogyakarta: Andi.

11. Sakur, Stendy B. (2005). Aplikasi Web Database dengan Dreamweaver MX 2004. Yogyakarta: Penerbit Andi. 